\title{
Congregational COVID-19 Conversations: Utilization of Medical-Religious Partnerships During the SARS-CoV-2 Pandemic
}

\author{
Kimberly Monson ${ }^{4} \cdot$ MopeninuJesu Oluyinka² - DanaRose Negro ${ }^{2}$. \\ Natasha Hughes ${ }^{2}$ - Daniella Maydan ${ }^{2}$ - Sahir Iqbal ${ }^{2}$ - Sherita H. Golden ${ }^{1,6}$. \\ Paula Teague $^{5}$ W. Daniel Hale ${ }^{2,4}$. Panagis Galiatsatos ${ }^{1,2,3}$ (D)
}

Accepted: 13 May 2021 / Published online: 25 May 2021

(c) The Author(s), under exclusive licence to Springer Science+Business Media, LLC, part of Springer Nature 2021

\begin{abstract}
Over the last 12-months during the pandemic caused by the severe acute respiratory syndrome coronavirus-2 (SARS-CoV-2), the Centers for Disease Control and Prevention (CDC) have issued public health instructions with the hope of mitigating the spread of the virus. Through existing relationships established by an academic hospital, we established weekly community conference calls to disseminate such critical information on the pandemic and allow community leaders to discuss struggles and successes. From these calls, we were able to collaborate in a more intimate manner with faith-based organizations, whereby we emphasized and planned the role they could undertake during the pandemic. Such emphasis was made between our medical institution and various faith-based organizations through meetings titled "Congregational COVID-19 Conversations." Over the past 12-months, we held virtual meetings with 38 faith-based organizations: 15 Christian congregations, 21 Jewish synagogues, and 2 Islamic masjids. We describe in detail in this report a narrative summary of the meetings. From these meetings, we discussed several COVID19-related themes that included how to have their place of worship disseminate public health messaging, aid in preparing buildings for public worship, and insight into preparing their regions for aid in both COVID-19 testing and for potential SARSCoV-2 vaccine sites. This medical-religious partnership has proven feasible and valuable during the pandemic and warrants emphasis in that it has the potential to serve a vital role in mitigating COVID-19-related disparities in certain communities, as well as potentially ending the COVID-19 pandemic completely.
\end{abstract}

Keywords COVID-19 · Medical-religious partnerships · Community engagement

Panagis Galiatsatos panagis@jhmi.edu

Extended author information available on the last page of the article 


\section{Introduction}

The ongoing pandemic caused by SARS-CoV-2 continues to impact countries and their respective communities ("Centers for Disease Control and Prevention", 2020; "World Health Organization," 2020). To mitigate the spread, engaging with communities must be prioritized to assure proper allocation of resources and information against SARSCoV-2 and its resulting disease, COVID-19 (Gilmore et al., 2020). Medical-religious partnerships in the past have been powerful to alleviate public health crises in communities, from HIV(Abara et al., 2015) to more recent coronavirus epidemics as seen by MERS-CoV (Alotaibi et al., 2017). Following along with such a collaboration, our organizations launched COVID-19-related Community Calls in March of 2020, aiming to disseminate up-to-date information on the pandemic, as well as assure allocation of resources, by utilizing our partnership with faith-based organizations.(Galiatsatos et al., 2020) These calls focus on local communities of Baltimore City and the state of Maryland region; thereby, relaying information not only from a national level, but local policies and restrictions impacting faith-based organizations. However, as the state of Maryland began to lift restrictions and allow organizations to reopen with limitations, faith leaders were forced to make decisions that had immediate impact on the health and well-being of their congregation and communities.

The Centers for Disease Control and Prevention (CDC) provided guidance and recommendations for faith-based organizations to educate, prepare, and respond to COVID-19 ("Centers for Disease Control and Prevention", 2021a,b). However, local faith-based leaders were still left challenged on how to take general guidelines and adapt them to their buildings of worship and their community. Differences in social structures, systems, and processes among communities and their respective social norms and beliefs affect health behaviors during infectious disease outbreaks (Kickbusch \& Reddy, 2016). Therefore, how people interact and engage through their social structures, specifically faith-based organizations, require considerations on how to effectively adapt and respond to COVID-19.

In an effort to assure accordance with CDC guidelines, the Healthy Community Partnership (HCP) and Medicine for the Greater Good (MGG) provide guidance to faith-based organizations who participate in our COVID-19 Community Calls. Specifically, we met with faith-based leaders to discuss how to implement CDC guidelines in accordance with their belief, place of worship, and community, in meetings titled "Congregational COVID-19 Conversations."

In this narrative review, we summarize our the public health messaging meant to allow faith-based leaders the comfort and confidence to have their places of worship adapt to the guidelines and be seen as a COVID-19 informational hub for their congregation and community. Further, we share brief insight into how such meetings and messaging were received by the faith-based organizations. 


\section{Congregational COVID-19 Conversations: Medical-Religious Meetings During the Pandemic}

Through the collaborative efforts of the Healthy Community Partnership (HCP), Medicine for the Greater Good (MGG), and the Department of Spiritual Care and Chaplaincy (DSCC), the hospital has established trusted relationships with over 500 individuals from local congregations. These individuals would join our COVID-19 related Community Calls, where faith-based leaders were offered the ability to virtually meet with our COVID-19 personnel (from HCP, MGG, and DSCC) to discuss how to reopen their place of worship safely. There was an overwhelming interest from our community to remain informed, keep current with both state and local policies and guidelines, and be proactive in keeping loved ones safe and healthy. Since May 2020, we held 58 virtual meetings with faith-based organizations, titling these meetings "Congregational COVID-19 Conversations." During these sessions, we discussed guidelines issued by the $\mathrm{CDC}$ on healthy hygiene practices, cleaning and disinfecting, and physical distancing, while tailoring to the needs and beliefs of the religious communities. All of these virtual meetings were completed by Zoom (San Jose, California), recorded on the Zoom platform, and then, the recording was shared with the congregations by email.

Below, we summarize the key tailored requests made by our COVID-19 team (personnel from MGG, HCP, and DSCC) for the congregations, as they prepared for reopening for their respective communities. These are highlighted in Table 1.

\section{Tailored COVID-19 Public Health Messaging for Congregations}

Identify COVID-19 leaders. Congregations were asked to identify two or more congregants to serve as COVID-19 leaders, and be liaisons between the faith-based organization and our COVID-19 pandemic response team through HCP and MGG. These community leaders would join our weekly community conference calls to receive critical information on the pandemic and share such information with their

Table 1 A summary of the tailored COVID-19 public health messaging discussed during the congregational COVID-19 conversations

\begin{tabular}{ll}
\hline Public Health Theme & Summary \\
\hline COVID-19 leaders & $\begin{array}{c}\text { Congregations were asked to identify several members to stay up-to-date with } \\
\text { COVID-19 information and be liaisons with our medical institution }\end{array}$ \\
Infectious control & $\begin{array}{l}\text { Emphasized stay-at-home policies for all persons with symptoms concerning for } \\
\text { COVID-19. For the congregation, an emphasis on hygienic interventions to be } \\
\text { adhered to, from face masks to physical distancing to hand hygiene }\end{array}$ \\
Rehearsal/trial runs & $\begin{array}{l}\text { Before reopening, congregations were encouraged to execute trial runs in an } \\
\text { effort to be prepared for when congregants and staff returned } \\
\text { All congregations were encouraged to take proper steps to record all attendees to } \\
\text { their building and execute contact tracing if one of the attendees was diagnosed } \\
\text { with COVID-19 }\end{array}$ \\
\hline
\end{tabular}


respective community members. Further, the identified congregant COVID-19 leaders would be responsive to the congregation's questions and concerns, relaying them to our medical center group as needed. Finally, the congregation COVID-19 leaders would stay up-to-date with current city and state policies and guidelines around COVID-19.

Infectious Control Practices. Faith leaders and their respective COVID-19 leaders were encouraged to implement two strategies regarding infectious control. First, a strict stay-at-home policy for staff and/or congregants who had symptoms that were known to be in accordance with COVID-19 (fevers, cough, dyspnea) or who have had close contact with a person with COVID-19 in the last 14 days. These congregants were encouraged to either discuss next steps for COVID-19 work-up with their healthcare professional or follow CDC guidelines on isolation. Second, infectious control policies centered on implementing hygienic interventions for asymptomatic congregants who would be attending the building. Staff and congregants were encouraged to wear face masks that covered from the bridge of their nose to the bottom of their chin and were multi-layered, promote hand cleaning through accessible hand sanitizers, and remain at least six feet apart from others. Of note, families who lived together could remain together as a cluster within the building. Recommendations were made for frequently touched surfaces and shared objects to be cleaned and disinfected regularly, especially if there were multiple services within the same day.

Trial/Rehearsal Runs. After the place of worship developed a plan of action to reopen safely, we recommended that the designated COVID-19 leaders and faith leader(s) arrange trial/rehearsal runs to ensure that all necessary precautions were taken and that operations ran smoothly. After such rehearsals, if any concerns were identified by the congregation leadership, they would notify us to further review and assist. Further, we were updated after congregations had public gatherings, as allowed by city and state authority, if there were any issues or concerns. Congregation COVID-19 leaders also shared their successes. Such insights allowed our team to continue to adapt our recommendations with the congregation, and others faithbased organizations; thereby, serving as a bidirectional communication channel that played a significant role in the pandemic.

Contact Tracing. Congregants and their respective COVID-19 leaders were encouraged to maintain attendance in some manner (e.g., physical attendance sheets, online registrations for congregation attendance) for each worship service, thereby, allowing them to perform contact tracing in an efficient manner if needed. The congregants were told during our meeting to notify their community members about contact tracing efforts and where the emphasis would be to mitigate the potential for the congregation becoming a "super-spreader" for SARS-CoV-2 ("Centers for Disease Control and Prevention," Contact Tracing, 2021ab). The efforts included (a) attending staff and/or congregants providing their respective contact information (telephone number and/or email address) and (b) having an open line of communication to share with the congregation COVID-19 leaders if one of the attendees was diagnosed with COVID-19. If a congregant was diagnosed with COVID-19 shortly after attending worship service, all staff and congregants would be notified about potential exposure while maintaining confidentiality. Staff and congregants with 
symptoms of COVID-19, or individuals with a positive COVID-19 diagnosis, would not return to the facility until they have met the CDC's criteria to discontinue home isolation ("Centers for Disease Control and Prevention", 2021a, b). Further, we suggested the facility stay closed for 14 days while being cleaned and disinfected before reopening to their community.

\section{Summary of Participating Faith-Based Organizations}

To date, we have delivered such tailored messaging to 58 Congregational COVID19 Conversations with 38 faith-based organizations, all of which were Abrahamic monotheistic religions: 15 Christian congregations, 21 Jewish synagogues, and 2 Islamic masjids. Fourteen of the faith-based organizations have held Congregational COVID-19 Conversations twice (all were Christian congregations), and six have held three Congregational COVID-19 Conversations (two were from masjids, two from synagogues, and two from Christian congregations). Of the 38 faith-based organizations, 10 identified with buildings that could hold a maximum of 50 occupants, 24 identified with buildings that could hold up to 200 occupants, and 4 identified with buildings that could hold more than 200. Table 2 summarizes the participating faith-based organizations.

\section{Building of Trust}

While much of the collaborations were with congregations with an established partnership and sense of trust, several faith-based organizations collaborated with the academic center for the first time due to the pandemic. Concerns were shared by the leaders regarding various COVID-19-related issues, from vaccine safety and hesitancy to assuring accurate information on COVID-19 was received; often, these contextual concerns either pre-dated the pandemic or emerged during it (Gilmore et al., 2020). To establish trust in both the academic center and the public health messaging, engagement during the meetings centered to active listening to the faith-based

Table 2 Summary of participating faith-based organizations

\begin{tabular}{llll}
\hline $\begin{array}{l}\text { Religious } \\
\text { denomination }\end{array}$ & $\begin{array}{l}\text { Number of participating faith- } \\
\text { based organizations }\end{array}$ & Geographic region & Special requests \\
\hline Christian & 15 & $\begin{array}{l}\text { Maryland: } 10 \\
\text { Michigan: } 3\end{array}$ & $\begin{array}{l}\text { Performing communion } \\
\text { Choir singing }\end{array}$ \\
& & Pennsylvania: 2 & Handling of collection plate \\
Islamic & 2 & Maryland: 2 & Executing baptisms \\
Judaism & 21 & Georgia: 1 & Gathering during Ramadan \\
& & Maryland: 19 & Executing brisses \\
& New York: 1 & Handling of a shofar \\
\hline
\end{tabular}


organization leadership and identifying each concern and the understanding around the concern. A two-way dialog developed between the community stakeholders and the academic medical center personnel and reaffirmed through multiple communication channels after the initial meeting (Gilmore et al., 2020). Further, consistency in accurate information was delivered in an efficient manner whenever concerns were raised over misconceptions or rumors. Such strategies assured trust was established and maintained during the COVID-19 pandemic with faith-based organizations.

\section{Brief Insight into Impact}

The ongoing COVID-19 pandemic is forcing congregations to adapt and learn so as to reconvene in-person services safely. Many faith-based leaders are learning to implement creative variations to faith-based practices such as in-service giving, baptisms, bris, and choir singing. These were discussed extensively during our congregational meetings, with such unique requests summarized in Table 2. Brief insight into the impact of the Congregational COVID-19 Conversations is summarized here, all of which were data collected through email corroborations after the completions of Congregational COVID-19 Conversations.

For instance, during our virtual meetings, we promoted physical distancing by encouraging faith-based organizations to limit the size of gatherings in accordance with the guidance and directives of state and local authorities. Spacing out seating for congregants who do not live in the same household to at least six feet part is an important aspect of a faith-based organization's action plan to reopen. Examples of our of COVID-19 request implemented include one local church placing post-it notes and tape throughout the sanctuary to provide congregants guidance on how to space themselves out safely. Another religious community chose to hold their services in their facility's parking lot in which congregants remain in their vehicles throughout the worship service.

An example of how contact tracing was effective in preventing a super spreading event includes another faith-based organization in Baltimore City. Days after a Sunday mass, the faith-based leader learned of a congregant who tested positive for the virus. Using the guidelines and recommendations shared during our virtual meeting, the faith-based leader and their respective COVID-19 identified leaders prepared a well-written letter for the congregation attendees outlining the circumstances and offering guidance, while also maintaining the individual's confidentiality. The congregation remained closed for 14 days as well and the building was disinfected. To date, all congregations we have met with have emphasized they have contact tracing strategies implemented, specifically with an attendance sheet for everyone who attends their place of worship for more than $15 \mathrm{~min}$.

As religious communities adopted their reopening plans, many faith-based leaders and their respective congregants shared with us how they were able to reopen their doors safely and effectively because of the guidance and support we provided during our virtual meetings. Below are sample commentaries take from emails sent from congregations and their congregants, each comment from a unique faithbased organization that we collaborated with; these were selected as we believe they 
highlight how the community utilized the information and/or appreciated it in real time.

- "Thank you so very much for this opportunity! We are very grateful and after additional conversation think we have a concrete plan to move forward. You are a blessing and a wonderful resource." (Congregant Leader)

- "Thanks so much for the guidance you both gave to my congregational leadership regarding reopening. The information was on point and very well received. We look forward to receiving the notes. Also, my brother-in-law shared with me that we're very pleased by what you shared with them. He had a small reopening Sunday and implemented your recommendations. He shared the video on their conference Facebook page and has had over 700 views with overwhelmingly positive responses. Thank you for the great work you are doing assisting the faith community with navigating these unchartered paths." (Congregational Member)

- "I have been a nurse for almost half of my life. I have not been working that long but I have put in over 25 years. Never in my life did I ever feel so threatened by anything like this virus. Even with a vaccine eventually, life will never be as before. This community outreach program will make all the difference to people being able to adjust their lives to the "new normal." I have learned a lot. Thank you so much.” (Congregational Member)

- "I so appreciate all of your help and wanted to let you know that our first indoor in person worship service went well on Sunday. People mostly kept their distance and there were some grumbles but for the most part people understand that this is what we need to do." (Congregant Leader)

- "We're taking initial steps to reopen based on information from the CDC, the City and updates from Medicine for the Greater Good. Thank you so much for your efforts to help during this pandemic." (Congregant Leader)

- "You provided invaluable guidance in helping our church develop a plan for reopening live services at our church. Thank you for hosting these meetings for the community." (Congregant Leader)

- "The clergy and lay leaders of the Episcopal Church in South Palm Beach County are very grateful for all the great information you provided at our Zoom meeting. As we prepare to reopen pour churches, schools, and special ministries, your guidance and expertise are a blessing." (Congregational Member)

\section{Conclusion}

As the pandemic is controlled and the impact of COVID-19 becomes manageable, implementation of prevention and control guidelines will change in an effort to allow communities to re-emerge into public spaces. For faith-based organizations, adapting to the re-emergence is challenging as guidelines fail to account for all specific religious gathering traditions and purposes. Through the actions of the discussed medical-religious collaborations, we were able to show that time spent with individual faith-based leaders and congregations can result in a significant positive community impact during the COVID-19 pandemic. Questions and concerns were 
answered and addressed in real time, and confidence was established for faith-based leaders to reopen their places of worship as well as disseminate COVID-19-related resources and information. Therefore, this medical-religious partnership has been proven to be feasible and valuable during the pandemic, warranting a permanent role as a public health tool to for this, and future, public health crises around infectious outbreaks.

\section{Declaration}

Conflict of interest The authors have no conflicts of interest and no financial disclosures to reveal and have no competing interests to declare.

\section{References}

Abara, W., Coleman, J. D., Fairchild, A., Gaddist, B., \& White, J. (2015). A faith-based community partnership to address HIV/AIDS in the southern United States: implementation, challenges, and lessons learned. Journal of Religion and Health, 54(1), 122-133. https://doi.org/10.1007/ s10943-013-9789-8

Alotaibi, M. S., Alsubaie, A. M., Almohaimede, K. A., Alotaibi, T. A., Alharbi, O. A., Aljadoa, A. F., Alhamad, A. H., \& Barry, M. (2017). To what extent are Arab pilgrims to Makkah aware of the middle east respiratory syndrome coronavirus and the precautions against it? Journal of Family and Community Medicine, 24(2), 91-96. https://doi.org/10.4103/2230-8229.205119

Centers for Disease Control and Prevention (CDC). (2020). Healthcare Facilities: Managing Operations During the COVID-19 Pandemic. https:/www.cdc.gov/coronavirus/2019-ncov/hcp/guidance-hcf. html. Accessed 11 January 2021.

Centers for Disease Control and Prevention (CDC). (2021). Considerations for Communities of Faith. https://www.cdc.gov/coronavirus/2019-ncov/community/faith-based.html Accessed 27 February 2021.

Centers for Disease Control and Prevention (CDC). (2021). Contact Tracing for COVID-19. https:// www.cdc.gov/coronavirus/2019-ncov/php/contact-tracing/contact-tracing-plan/contact-tracing.html. Accessed 5 March 2021.

Galiatsatos, P., Monson, K., Oluyinka, M., Negro, D., Hughes, N., Maydan, D., Golden, S. H., Teague, P., \& Hale, W. D. (2020). Community Calls: Lessons And Insights Gained From A Medical-Religious Community Engagement During the COVID-19 pandemic. Journal of Religion and Health, 59(5), 2256-2262. https://doi.org/10.1007/s10943-020-01057-w

Gilmore, B., Ndejjo, R., Tchetchia, A., De Claro, V., Mago, E., Lopes, C., \& Bhattacharyya, S. (2020). Community engagement for COVID-19 prevention and control: a rapid evidence synthesis. BMJ Global Health., 5(10), e003188. https://doi.org/10.1136/bmjgh-2020-003188

Kickbusch, I., \& Reddy, K. S. (2016). Community matters - why outbreak responses need to integrate health promotion. Global Health Promotion, 23(1), 75-78. https://doi.org/10.1177/1757975915 606833

World Health Organization. (2020). Coronavirus disease (COVID-19) pandemic. https://www.who.int/ emergencies/diseases/novel-coronavirus-2019 Accessed 2 March 2021.

Publisher's Note Springer Nature remains neutral with regard to jurisdictional claims in published maps and institutional affiliations. 


\section{Authors and Affiliations}

Kimberly Monson ${ }^{4} \cdot$ MopeninuJesu Oluyinka ${ }^{2} \cdot$ DanaRose Negro ${ }^{2} \cdot$ Natasha Hughes ${ }^{2}$. Daniella Maydan ${ }^{2}$. Sahir Iqbal ${ }^{2}$. Sherita H. Golden ${ }^{1,6}$. Paula Teague $^{5} \cdot$ W. Daniel Hale ${ }^{2,4} \cdot$ Panagis Galiatsatos ${ }^{1,2,3}$

1 Office of Diversity, Inclusion, and Health Equity, Johns Hopkins Medicine, Baltimore, MD, USA

2 Medicine for the Greater Good, Johns Hopkins Bayview Medical Center, 4940 Eastern Avenue; 4th Floor, Asthma and Allergy Building, Baltimore, MD 21224, USA

3 Division of Pulmonary and Critical Care Medicine, Department of Medicine, Johns Hopkins School of Medicine, Baltimore, MD, USA

4 Healthy Community Partnership, Johns Hopkins Bayview Medical Center, Baltimore, MD, USA

5 Department of Spiritual Care and Chaplaincy, Johns Hopkins Health System, Baltimore, MD, USA

6 Departments of Medicine and Epidemiology, Johns Hopkins University, Baltimore, MD, USA 